\title{
ENTRE NORMA E USO, FALA E ESCRITA: CONTRIBUIÇÕES DA SOCIOLINGUÍSTICA À ALFABETIZAÇÃO
}

FREITAG, Raquel Meister $\mathrm{Ko}^{1}$

RESUMO: Neste texto, são discutidos alguns conceitos sociolinguísticos essenciais para que o professor alfabetizador tenha êxito em seu propósito: as questões referentes à norma e ao uso da língua e sua relação com a fala e a escrita. Para ilustrar a discussão, são elencados resultados acerca da relação entre fala e escrita no rotacismo (neutralização dos traços fonéticos de /l/ e de /r/), fenômeno fonológico variável no português, fortemente estigmatizado e sensível aos contínuo da escolarização e urbano-rural.

Palavras-chave: Norma lingüística. Sociolinguística. Alfabetização.

SUMMARY: In this text, some essentials sociolinguistics concepts are discussed to collaborate with the purpose alphabetization teacher: questions about the language rules and the usage and its relation with spoken language and written language. Data about rotacism (neutralization of phonetic features of $/ \mathrm{l} / \mathrm{and} / \mathrm{r} /$ ) - variable phonologic phenomena in Portuguese strongly stigmatized and sensible to school and rural-urban clines - in the spoken language and written language illustrate this relation.

Keywords: Linguistic rule. Sociolinguistic. Alphabetization.

\section{INTRODUÇÃOO}

Ao chegar à escola, toda criança, em condições normais de desenvolvimento, já é dotada de competência gramatical e comunicativa na sua língua materna, antes de ser alfabetizada. A alfabetização é o processo em que a criança vai aprender especificamente o código escrito da sua língua materna. Trata-se de um processo de apropriação de tecnologia, que exige dos professores empenhados em tal tarefa conhecimentos específicos de Linguística. O professor deve, por exemplo, reconhecer que cada criança vem de uma realidade sociolinguística diferente, e que essas diferenças irão se manifestar no modo como as crianças irão aprender o código escrito. Neste texto, primeiramente, são discutidos alguns dos conhecimentos linguísticos necessários para que o professor de língua materna possa analisar e trabalhar a escrita dos alunos. Em um segundo momento, são analisados resultados de um fenômeno sociolinguístico do português - o rotacismo - com o propósito de evidenciar como a realidade sociolinguística do alfabetizando manifesta-se no seu aprendizado do código escrito.

\footnotetext{
${ }^{1}$ Prof. ${ }^{a}$ da Universidade Federal de Sergipe. Dra. em Linguística pela Universidade Federal de Santa Catarina. Coordenadora institucional do projeto Ler + Sergipe: leitura para o letramento e cidadania (CAPES/INEP Programa Observatório da Educação 2010).
} 


\section{UMA CONCEPÇÃO DE LINGUAGEM}

Embora linguagem e língua sejam noções interligadas ${ }^{2}$, a primeira é mais abrangente que a segunda. O termo linguagem costuma ser associado a palavras como 'faculdade', 'capacidade', 'atividade', com foco ora na função cognitiva/biológica, ora na função comunicativa/social da linguagem humana. A linguagem é uma atividade cognitiva e discursiva, já que ela mantém um vínculo estreito com o pensamento e também estabelece a interlocução. Através dela "se estabelecem quadros de referências culturais [...] pelos quais se interpretam a realidade e as expressões linguísticas. [...] Como atividade sobre símbolos e representações, a linguagem torna possível o pensamento abstrato.” (BRASIL, 1998a, p. 20). E através dela também se estabelece "ação interindividual orientada por uma finalidade específica, um processo de interlocução que se realiza nas práticas sociais existentes nos diferentes grupos de uma sociedade, nos distintos momentos de sua história". (BRASIL, 1998a, p. 20.) Em resumo, pela linguagem se expressam pensamentos, ideias e intenções, se promovem relações interpessoais. Observe-se a seguinte passagem dos PCNs, em que a noção de língua como conhecimento implícito, se mescla com a noção de usos historicamente situados dos quais aflora o vernáculo ${ }^{3}$ :

Desde a infância, todos os falantes de uma língua comunicam-se com base em uma gramática internalizada, que independe da aprendizagem sistemática, pois se adquire pelo contato com os demais falantes. É a partir desse saber linguístico implícito que os usuários se fazem entender, de uma forma ou de outra, e deixam transparecer as marcas de sua origem, idade, nível sociocultural. (BRASIL, 1998b, p. 57)

A língua, na perspectiva sociolinguística, é concebida como um sistema heterogêneo, portanto sujeito a variações e mudanças no espaço e no tempo. As diferenças linguísticas costumam ser reunidas em três tipos de variação: a variação regional ou geográfica (diatópica), a variação social (diastrática), e a variação estilística ou de registro mais ou menos formal (diafásica). Podemos ainda considerar uma quarta variação, decorrente da modalidade oral ou escrita da língua (diamésica). Todos os tipos de variação ocorrem nos diferentes níveis linguísticos: fonético-fonológico (ex.: <peixe pexi>; <mulher muié>); morfológico (ex.: <colherinha colherzinha $>$; $<$ menininho $\sim$ meninote $>$ ); sintático (ex.: $<a$ gente canta $\sim$ a gente cantamos $\rangle$; $\langle\varnothing$ estudo $\sim$ eu estudo $>$ ) ; lexical (ex.: <pandorga papagaio pipa>); discursivo (ex.: <sabe? entende?>; <acho que $\sim$ parece $>$ ).

\footnotetext{
${ }^{2}$ Em Gorski e Freitag (2007) pode-se encontrar uma ampla e detalhada discussão sobre concepções de língua, linguagem e gramática. Na base de qualquer reflexão sobre o ensino de língua, os termos linguagem, língua, norma e gramática são de uso comum inclusive entre os leigos e representam conceitos nada triviais, uma vez que diferentes teorias linguísticas recortam e definem de modo diferente seus objetos; cada concepção de língua(gem) tem correlata uma certa concepção de gramática; o conceito de norma linguística está atrelado à visão de gramática; enfim, os termos em pauta são, no mínimo, polissêmicos. Existe, assim, uma estreita correlação entre as diferentes concepções de língua(gem) e as concepções de gramática.

${ }^{3}$ Vernáculo é o estilo em que é dada monitoração mínima, isto é, em que se presta o mínimo de atenção à fala (LABOV, [1972] 2008, p. 63).
} 
A variação geográfica carrega fortes marcas identitárias: o indivíduo praticamente se identifica, revela sua origem regional, ao falar. A variação social também carrega marcas identitárias e se manifesta nas diferentes normas: a norma culta é usada pelas pessoas mais diretamente relacionadas com a cultura escrita que é historicamente legitimada (pessoas com alto grau de escolarização), ao passo que as normas ou variedades não-padrão são utilizadas por indivíduos não escolarizados ou pouco escolarizados. As variedades culta e não-padrão usualmente refletem as diferenças sociais dos falantes. A norma culta, vista por muitos como o "falar corretamente", é considerada uma via de ascensão social. Quem não domina a variedade padrão da língua é marginalizado, ridicularizado, enfim, excluído: em uma entrevista para emprego, na escola, no vestibular. Porém, o domínio e o uso da variedade culta ficam restritos a uma parte muito pequena da população brasileira, que, não por coincidência, é a detentora do poder político e econômico.

No que diz respeito às variedades linguísticas, é papel da escola ensinar a 'norma culta' da língua, que é a variedade de prestígio na sociedade. Entretanto, a variedade linguística que o aluno traz de casa nunca deve ser desconsiderada e tachada de "erro". O que os professores devem fazer é considerar os diferentes níveis de conhecimento prévio que os alunos apresentam e promover a ampliação desses conhecimentos, criando situações comunicativas diferenciadas para que os alunos estendam gradativamente o conhecimento linguístico já adquirido. Muitas vezes as diferenças entre as variedades dos alunos e a variedade da escola são tão grandes que parece estarmos diante de duas línguas diferentes. E essas diferenças são ainda mais salientes no momento de aprendizado do código escrito da língua.

\section{CONHECIMENTOS SOBRE ASPECTOS FONÉTICOS DE DIFERENTES VARIEDADES DA LÍNGUA}

A análise de textos produzidos por crianças que estão aprendendo o código escrito da sua língua materna revela a maneira como os aprendizes inconscientemente registram aspectos fonéticos da modalidade sociolinguística regional que utilizam. Ao iniciar seu intercurso no mundo da escrita, a criança tende a estabelecer uma correspondência estrita entre os sons da fala e as letras, numa atitude semelhante à do linguista ao fazer uma transcrição fonética. No princípio do aprendizado do código escrito da sua língua materna, a criança constrói hipóteses acerca da representação dos sons, tomando por base seus conhecimentos da fala da sua variedade sociolinguística. 
oral (inclusive e principalmente a de natureza regional) se reduz a uma ortografia fixa e invariável, cuja transgressão não é uma opção aberta para o usuário da língua. Assim, o texto escrito pode ser lido e entendido por falantes com os mais diferentes antecedentes regionais. Estamos pois diante de dois estatutos bem distintos. Ensinamos nossos alunos a usar os recursos da variação oral para tornar sua fala mais competente, preservando contudo suas características sociodemográficas, e ensinamos nossos alunos a usar a ortografia: a grafia normatizada, fixada, canônica. (BORTONI-RICARDO, 2004, p. 273).

Veja-se o que ocorre com o fenômeno do rotacismo no português. Do ponto de vista fonético, as consoantes /l/ e /r/ são muito próximas, podendo, por isso, intercambiar-se ou neutralizarem-se. Seus traços articulátorios são definidos no quadro 1.

\begin{tabular}{lcc}
\hline & $/ 1 /$ & $/ \mathrm{r} /$ \\
\cline { 2 - 3 } Ponto de articulação & alveolar & Alveolar \\
Modo de articulação & lateral & Vibrante \\
Ressonância & oral & Oral \\
Vibração laríngea & sonora & Sonora
\end{tabular}

Quadro 1: Traços articulatórios das consoantes /1/ e /r/ Fonte: (CRISTOFARO-SILVA, 1999)

Como pode ser observado no quadro 1 , a diferença entre as consoantes resume-se ao modo de articulação: enquanto a primeira é lateral (o som é produzido à medida que o ar escapa pelos lados de um obstáculo formado no centro da cavidade bucal pelo contato do ápice da língua com os alvéolos), a segunda é vibrante simples (o som é produzido à medida que o ar escoa por uma passagem estreita formada por um toque rápido do ápice da língua contra os alvéolos).

Porém, apesar da semelhança do ponto de vista articulatório, as consoantes /l/ e /r/ constituem fonemas distintos no português, uma vez que podem contrastar em ambiente idêntico. Aplicando-se o princípio da comutação a pares mínimos, a troca de $/ 1 / \mathrm{por} / \mathrm{r} / \mathrm{implica}$ em mudança de significado: / 'kala / é diferente de / 'kara /; / 'atlas / é diferente de / a'tras /.

E, do ponto de vista sociolinguístico, as consoantes /1/ e /r/ também se parecem quanto ao potencial de variação. Estão sujeitas a inúmeros processos de variação dialetal, por vezes, neutralizando os traços contrastivos e transforando-se em alofones posicionais, tais como no rotacismo.

O fonema /1/, quando funciona como segunda consoante prevocálica nos cluster consonantais, está sujeito ao processo de rotacismo, do qual derivam formas como ['kraru], ['krawdia], ['broku], entre outras. De acordo com Coutinho (1979), na passagem do latim ao português, o processo agiu intensamente convertendo formas como ecclesia-, plaga-, esclavufluxu- em igreja, praia, escravo, frouxo. 
Variedades linguísticas em que ocorre o rotacismo costumam ser associadas a comunidades rurais e são estigmatizadas. Entretanto, trata-se de variantes linguísticas de milhares de brasileiros falantes das variedades não-padrão, a "classe social desprestigiada, marginalizada, que não tem acesso à educação formal e aos bens culturais da elite", para quem a fonética da norma culta é como a de uma língua estrangeira.

As escolas de zona rural ou de periferia atendem a uma clientela com características
socioculturais específicas, que se distinguem das características da clientela das
escolas urbanas dos bairros de classe média, principalmente no que se refere ao
repertório linguístico. Estas especificidades não são devidamente contempladas nos
livros didáticos nem tampouco nas propostas curriculares, cabendo aos professores
de crianças provenientes de uma cultura iletrada a pesada tarefa de fazer a adequação
dos conteúdos programáticos aos antecedentes culturais de seus alunos. Alguns
desses professores são membros da comunidade onde trabalham, outros são
'forasteiros', com background cultural diferente. Tanto uns quanto outros, porém,
precisam aprender a identificar as características sociolinguísticas e culturais de seus
alunos, de forma sistemática. Esta identificação é pré-requisito para a implementação
de estratégias pedagógicas e interacionais que sejam sensíveis aos traços culturais
dos alunos e proporcionem melhores resultados de aprendizagem. (BAGNO, 2001,
p. 42).

Para identificar as características sociolinguísticas e culturais dos alunos de forma sistemática, é preciso que os conhecimentos (socio)linguísticos decorrentes das pesquisas atuais sobre educação em língua materna façam parte da formação do professor alfabetizador. Soares $(1998$, p.8) apresenta o que seria o mínimo que um professor alfabetizador deveria aprender em sua formação:

Um alfabetizador precisa conhecer os diferentes componentes do processo de alfabetização e do processo de letramento. Conhecer esses processos exige conhecer, por exemplo, as práticas sociais e usos da língua escrita, os fundamentos do nosso sistema de escrita, as relações fonema/grafema que regem nosso sistema alfabético, as convenções ortográficas... exige ainda a apropriação do conceito de texto, de gêneros textuais... Mas, além de conhecer o objeto da aprendizagem, seus componentes linguísticos, sociais, culturais, o alfabetizador precisa também saber como é que a criança se apropria desse objeto, ter uma resposta para a pergunta: "como é que se aprende a ler e a escrever? A ler e produzir textos de diferentes gêneros?". Isso significa conhecer o processo de compreensão e produção de texto escrito, o processo de construção de sentido para um texto, o processo de desenvolvimento da fluência na leitura, os processos de aquisição e desenvolvimento de vocabulário, de que dependem a compreensão e a construção de sentido... $\mathrm{O}$ alfabetizador tem de conhecer o objeto da aprendizagem e também o processo pelo qual se aprende esse objeto, a língua escrita. Infelizmente esses conhecimentos ainda não entraram na formação dos alfabetizadores. (SOARES, 1998, p.8, grifos da autora)

Casos como o do rotacismo costumam provocar reações de preconceito linguístico, principalmente naquelas pessoas que se situam nos pontos mais altos na pirâmide social, ou seja, que pertencem a um nível sócio-econômico mais alto e que dominam a variedade culta da língua. O preconceito linguístico se manifesta em comentários do tipo: "fulano fala errado", "fulano não sabe falar direito", "a fala de fulano é feia"... A isso se chama valor 
social das formas variantes. A fala (ou escrita) é avaliada ou julgada em função do status social dos indivíduos que a utilizam, e não pelas características linguísticas em si.

\section{ROTACISMO NA FALA E NA ESCRITA}

Como vimos, o rotacismo é um fenômeno regular e recorrente no português. Ainda assim, é alvo de estigma. Alinhado a estudos que tratam deste fenômeno (cf. COX; ASSAD, 1999; FREITAG et al., 2010), trazemos resultados de um estudo realizado para averiguar o efeito da variedade linguística da criança em processo de aprendizado do código escrito da sua língua materna, mais especificamente, o efeito do fenômeno do rotacismo, em alunos de uma escola da zona rural de Ribeirópolis, município do Agreste Central Sergipano (SANTANA et al., 2008). Foram escolhidos seis itens lexicais contendo o cluster consonantal $/ \mathrm{Cl} /$, cuja representação é um dígrafo (planta, flor, bloco, blusa, placa, globo). Os alunos foram expostos a um ditado visual (no qual eram expostos a figuras representando os itens lexicais alvo) e a um ditado oral (no qual as pesquisadoras ditavam os itens lexicais observando a variedade de prestígio, ou seja, /1/). A figura 1 ilustra a ocorrência das variantes no ditado visual.
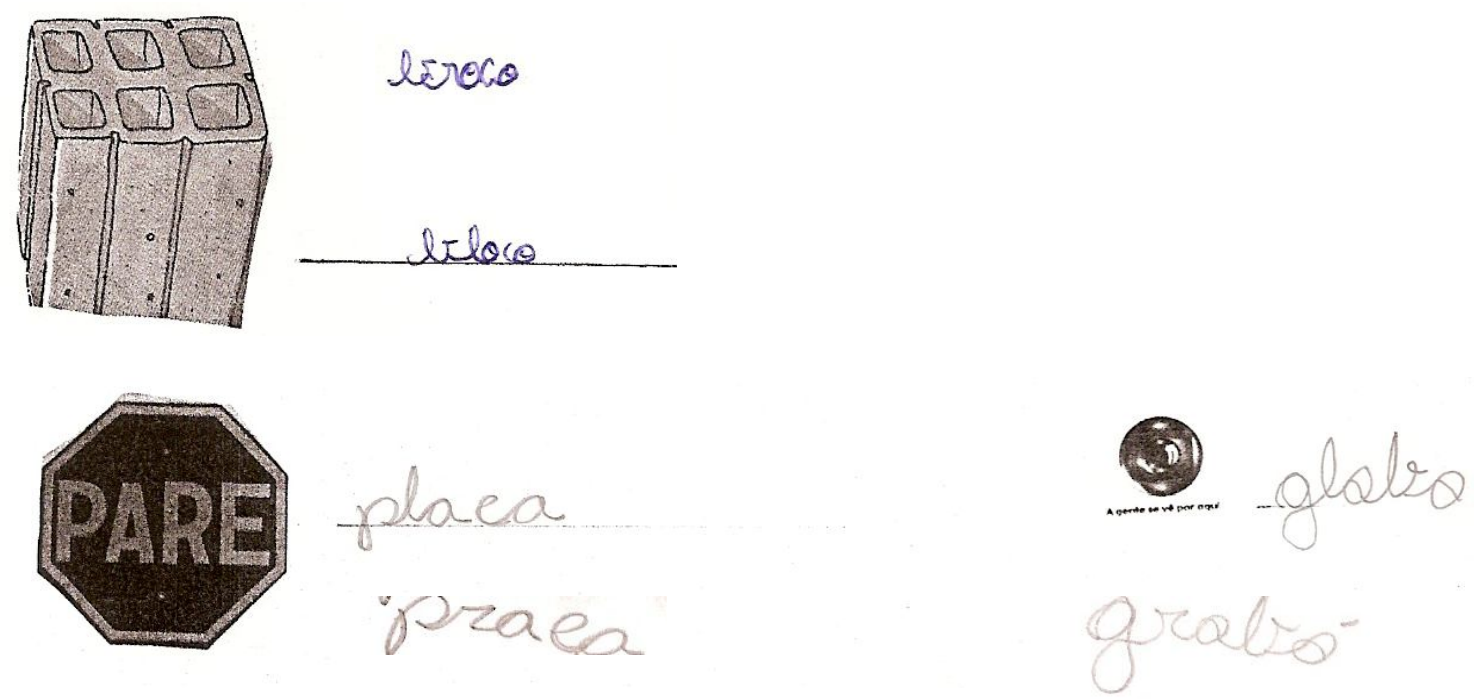

Figura 1: Ocorrências da variante padrão e não-padrão no cluster $/ \mathrm{Cl} / \mathrm{em}$ ditado visual

Inicialmente, a amostra previa alunos da $2^{\mathrm{a}}$ e da $4^{\mathrm{a}}$ série; entretanto, os alunos da $2^{\mathrm{a}}$ série não conseguiram executar nenhuma das duas atividades (nem oral, nem visual). Assim, os dados de análise resultantes são apenas da $4^{\mathrm{a}}$ série, nível em que se esperaria um relativo domínio das regras de conversão de fonemas em grafemas, ou seja, aprendizado pleno do código escrito da língua. 
Foram considerados 145 sujeitos, o que totalizou 893 dados (é preciso considerar que no ditado visual nem todos os itens lexicais foram interpretados conforme o previsto: para blusa, houve respostas como camisa ou vestido; para planta, árvore ou galho, entre outros), como ilustra a figura 2.
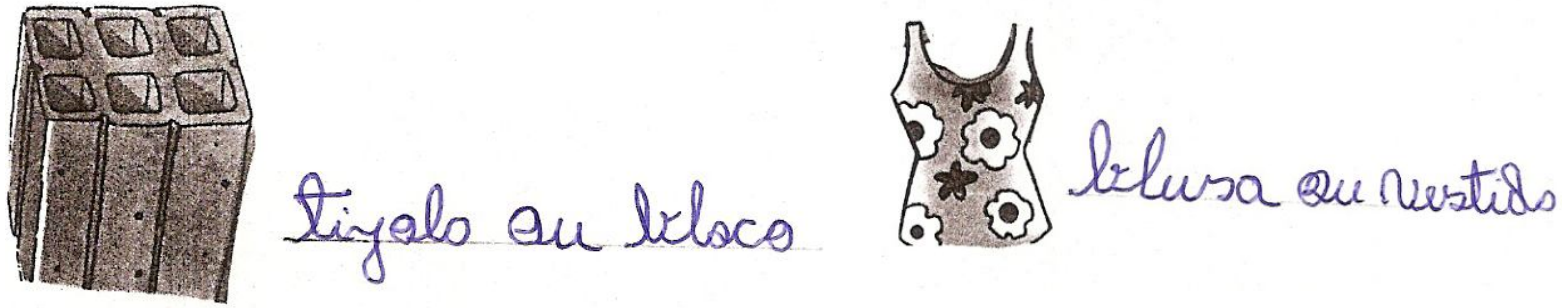

Figura 2: Ocorrências de outras respostas no ditado visual

Os resultados quantitativos foram obtidos de acordo com a metodologia da sociolinguística quantitativa (cf. LABOV [1972] 2008), com a codificação dos dados e submissão ao pacote estatístico GoldVarbX (SANKOFF; TAGLIAMONTE; SMITH, 2005). Foi realizada uma análise binomial, e os fatores "vocábulo", apresentado na tabela 1, e "tipo de estímulo" apresentado na tabela 2, mostraram-se estatisticamente significativos.

Tabela 1: Distribuição das frequências da variante padrão (vs. a não-padrão) quanto ao vocábulo

\begin{tabular}{lccc}
\hline & \multicolumn{2}{l}{ Aplicação/total } & Percentual \\
\cline { 2 - 4 } Placa & $145 / 160$ & $91 \%$ & 0,28 \\
Bloco & $106 / 120$ & $88 \%$ & 0,22 \\
Planta & $127 / 128$ & $99 \%$ & 0,83 \\
Blusa & $127 / 147$ & $86 \%$ & 0,20 \\
Flor & $175 / 176$ & $99 \%$ & 0,88 \\
Globo & $152 / 162$ & $94 \%$ & 0,39 \\
Total & $832 / 893$ & $93 \%$ & -- \\
\hline
\end{tabular}

Para entender a importância do tipo de vocábulo na escolha entre as variantes padrão e não-padrão de realização do cluster $/ \mathrm{C} l /$ é preciso rememorar que a escola que subsidiou a análise está localizada na região rural. Os vocábulos "flor" e "planta" são os que mais favorecem a aplicação da variante padrão, com pesos relativos de 0,88 e 0,83, respectivamente. São vocábulos relacionados ao contexto de mundo do universo rural, e que costumam ser utilizados pelos professores nas lições. Possivelmente, o contato prévio com em contexto de aprendizado levou os alunos a internalizarem a forma padrão. 
Tabela 2: Distribuição das frequências da variante padrão (vs. a não-padrão) quanto ao tipo de estímulo

\begin{tabular}{lccc}
\hline & \multicolumn{2}{c}{ Aplicação/total } & Percentual \\
\hline Ditado oral & $268 / 297$ & $90 \%$ & 0,38 \\
Ditado visual & $564 / 596$ & $95 \%$ & 0,55 \\
\hline Total & $832 / 893$ & $93 \%$ & -- \\
\hline
\end{tabular}

Os resultados obtidos também apontam que o tipo do estímulo - se oral ou visual desempenha papel significativo na escolha das formas variantes. No ditado oral, o percentual de uso da variante padrão ("pranta", 'grobo") é de $90 \%$, ao passo que no ditado visual, o percentual de uso da variante padrão sobe para $95 \%$. Os pesos relativos, entretanto, reforçam a tendência de uso sinalizada nos percentuais: o estímulo visual tende a favorecer o uso da variante padrão, com peso relativo de 0,55 , ao passo que o estímulo oral tende a restringir o uso da variante padrão, com peso relativo de 0,38 , Pode-se traçar a relação entre o estímulo oral e a variedade sociolinguística do aluno, que possui a realização de /r/ nos contextos em que a variedade padrão espera /1/, e o estímulo visual e a variedade escrita, aprendida na escola. Na verdade, não existem fronteiras rígidas, nem entre as variedades padrão e nãopadrão, nem entre as modalidades oral e escrita da língua. Bortoni-Ricardo (2004, p.61) propõe que pensemos na ideia de um contínuo (a autora propõe três: contínuo de urbanização, contínuo de oralidade-letramento e contínuo de monitoração estilística), representado numa linha imaginária que tem, localizada em cada extremidade, uma certa variedade ou modalidade. Estudando as interações em sala de aula, a autora trabalha com as noções de "evento de oralidade" e "evento de letramento", representados sob a forma de contínuo, na figura 3.

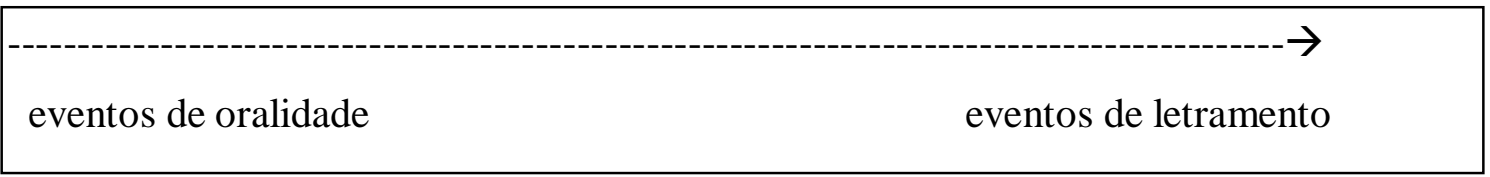

Figura 3: contínuo da oralidade e do letramento (BORTONI-RICARDO, 2004, p. 62)

No caso da sala de aula, por exemplo, um evento de letramento pode ser permeado de eventos de oralidade. Os eventos de letramento são mediados pela língua escrita (exposição de um conteúdo a partir de um roteiro escrito, fala simultânea à escrita no quadro-de-giz, aula de leitura, ditado, etc). Já os eventos de oralidade são intervenções curtas do professor, brincadeiras motivadoras, ou seja, situações de interação não mediadas pelo texto escrito (ex.: 
“Abram o livro na página tal", "Vamu ficar quietos", etc) (BORTONI-RICARDO, 2004, p. 26).

Bortoni-Ricardo (2006, p. 268) destaca que o professor alfabetizador precisa "fazer a distinção entre problemas na escrita e na leitura que decorrem da interferência de regras fonológicas variáveis e outros que se explicam simplesmente pela falta de familiaridade do alfabetizando com as convenções da língua escrita". E, ao considerar que as duas características principais das línguas são a variação e a mudança, o professor terá condições de promover a educação em língua materna, especialmente nas séries iniciais, com vistas a alfabetizar letrando ou letrar alfabetizando (SOARES, 1998).

\title{
CONSIDERAÇÕES FINAIS
}

A análise do fenômeno do rotacismo em alunos da $2^{\mathrm{a}}$ série de uma escola da região rural de Ribeirópolis/SE reflete a necessidade, por parte do professor alfabetizador, de ter conhecimento acerca dos pressupostos teóricos da sociolinguística para ter êxito em seu propósito. Neste sentido, cabe lembrar as palavras de Mírian Lemle:

\begin{abstract}
$\mathrm{O}$ professor que não tem preparo para entender o fenômeno da mudança linguística com a mesma naturalidade com que entende o fenômeno da evaporação ou da condensação da água é presa fácil de uma teorização preconceituosa dos fatos da língua. E uma teorização tremendamente perniciosa. Esse professor, que não entende o fenômeno da mudança da língua, acaba fatalmente acreditando na ideia de que a língua escrita é a língua certa e que tudo aquilo que não é igual ao certo é errado. Todos aqueles que falam errado são inguinorantes. Ao professor, cabe reprová-los. E a situação se eterniza. (LEMLE, 1991, p.63-4).
\end{abstract}

Para atender a esta demanda, ações como as prospectadas pelo projeto Ler + Sergipe: leitura para o letramento e a cidadania (Observatório da Educação 2010 - CAPES/INEP) focam a implantação de maneira otimizada das contribuições da Psicolinguística Aplicada e da Sociolinguística Educacional, ressaltando a importância de se trabalhar a consciência fonológica a partir do contato entre a variedade linguística que o aprendiz traz de casa e a variedade ensinada na escola.

\section{REFERÊNCIAS}

BAGNO, M. A norma linguística. São Paulo: Loyola, 2001.

BORTONI-RICARDO, S.M. Educação em língua materna: a sociolinguística na sala de aula. São Paulo: Parábola, 2004. 
BORTONI-RICARDO, S.M. O estatuto do erro na língua oral e na língua escrita. In: GORSKI, E. M.; COELHO, I. L. (Orgs.). Sociolinguística e ensino: contribuições para formação do professor de língua. Florianópolis: EdUFSC, 2006, p. 267-276.

BRASIL. Ministério da Educação e do Desporto. Secretaria de Educação Fundamental. Parâmetros curriculares nacionais terceiro e quarto ciclos do ensino fundamental: introdução aos parâmetros curriculares nacionais. Brasília, DF: MEC/SEF, 1998a. 174p.

BRASIL. Ministério da Educação e do Desporto. Secretaria de Educação Fundamental. Parâmetros curriculares nacionais terceiro e quarto ciclos do ensino fundamental: Língua Portuguesa. Brasília, DF: MEC/SEF, 1998b. 106 p.

CRISTÓFARO SILVA, T. Fonética e fonologia do português. São Paulo: Contexto, 1999.

FREITAG, R. M. Ko et al. Vamos prantar frores no grobo da terra: estudando o rotacismo nas séries iniciais da rede municipal de ensino de Moita Bonita/SE. RevLet - Revista Virtual de Letras, v. 2, p. 17-31, 2010.

GORSKI, E. M.; FREITAG, R.M. Ko. Freitag. Língua materna e ensino: alguns pressupostos para a prática pedagógica. In: SILVA, C.R. da (org). Ensino de português: demandas teóricas e práticas. João Pessoa: Ideia, 2007, p. 91-125.

LABOV, W. Padrões sociolinguísticos. São Paulo: Parábola, 2008 [1972].

SANKOFF, D.; TAGLIAMONTE, S.; SMITH, E. Goldvarb X: a variable rule application for Macintosh and Windows. Department of Linguistics of University of Toronto, Department of Mathematics - University of Ottawa, 2005.

SANTANA, A.R. de et al. O tratamento do rotacismo nas séries iniciais da rede municipal de ensino de Ribeirópolis. In: SILVA, L.R. da; FREITAG, R. M.Ko. (org). Linguagem e representação discursiva. João Pessoa: Universitária UFPB, 2008, p. 147-155.

SOARES, M. B. Alfabetização e letramento. São Paulo: Contexto, 2003.

SOARES, M. B. Entrevista: nada é mais gratificante do que alfabetizar. Letra A: o jornal do alfabetizador. Belo Horizonte: CEALE, n. 1, v. 1, p. 6-9, 2005. 